\title{
Influence of mechanical-biological pretreatment of municipal solid waste on landfill behaviour
}

Mechanical-biological pretreatment of municipal solid waste (MSW) can significantly improve the behaviour of landfills. Chemical oxygen demand (COD) and total nitrogen in the leachate, as well as the gas production rate, are about $90 \%$ lower than for untreated waste. The volume to be landfilled decreases by mechanical-biological pretreatment by up to $60 \%$.

\author{
K. Leikam \\ R. Stegmann \\ Technical University of Hamburg-Harburg, Hamburg, \\ Germany
}

Keywords - Composting; landfill simulation test; mechanical-biological pretreatment; municipal solid waste (MSW); reduction of emission potential

Corresponding author: K. Leikam, Technical University of Hamburg-Harburg, Harburger Schloßstr. 37, 21071 Hamburg, Germany

\section{Introduction}

By the mechanical-biological pretreatment of MSW or residual municipal solid waste (RMSW, i.e. the remaining MSW after separate collection of vegetative waste and packaging material), processes taking place in the landfill over long periods of time will be shortened to a few years. Emission potential contained in the waste is, to a large extent, reduced during pretreatment so that, compared with non-pretreated wastes, only minor emissions occur. These can be controlled and treated with little expenditure. The objective of mechanical-biological pretreatment is not to produce 'compost' to be applied in agriculture or horticulture as the content of heavy metals and other harmful substances is too high.

As a result of the thresholds given by the Technical Regulation on Municipal Solid Waste (TASi) in Germany, the mechanical-biological treatment of RMSW is not allowed. The limiting value of $5 \%$ for volatile solids (VS) corresponding to $3 \%$ total organic carbon (TOC) cannot be observed (more details about the landfill criteria of TASi are given in Heerenklage \& Stegmann 1995, as well as Stief 1993). However, many communities in Germany would prefer biological rather than thermal pretreatment (mainly due to the fact that costs for incineration are higher and that incinerators require a capacity of at least $>150000$ to 200000 $\mathrm{ta}^{-1}$ in order to avoid significantly higher costs). Also, estimation of the an incinerator's capacity is difficult because of the decreased amount of waste as a result of waste avoidance.

Another factor is that many communities do not produce so much waste. As a consequence in areas of low population density, long transport distances have to be faced. For these reasons the discussion about mechanical-biological pretreatment as an alternative to or in combination with incineration is still going on.

\section{Mechanical and biological treatment of RMSW}

\section{Effect of mechanical treatment}

During mechanical preparation, RMSW is pretreated and separated according to its material properties by means of shredding, screening, sorting and separation of ferrous components. By shredding, a reduction in volume and an increase in the specific surface of the wastes is attained. As a result of this enlargement, the biological degradation taking place in the subsequent biological pretreatment step is enhanced.

To enable a material-specific treatment of the RMSW, it can be separated into a fraction of a high calorific value, such 
as refuse-derived fuel (RDF) and into an organically enriched fraction which is stabilized through biological treatment. The separation can be achieved by sieving the RMSW using a screen size between 60 and $100 \mathrm{~mm}$; in many cases rotating sieve drums are used. A grain size distribution of unshredded RMSW shows that by using a mesh size of $80 \mathrm{~mm}$ over $90 \%$ of the vegetable residues are found in the sieve underflow and nearly $70 \%$ of materials with a high calorific value (like paper and plastics) are found in the sieve overflow (see Leikam \& Stegmann 1995).

Hand-picking to gain recyclables and to remove hazardous waste from the RMSW is not recommended. The recovery of materials is in general not useful owing to the contamination of papers and plastics by vegetable residues or soil. For this reason there is no market for these products. A problem associated with hand-picking is the contaminated air with fungi, germs and spores. To minimize the health risk to operators an exhaust air system and treatment is necessary. In total the efficiency of hand-picking in relation to the cost of the exhaust air system is very low. Only during the waste rcceipt is presorting useful to remove interfering materials (like large stones and wheels) to protect the following aggregates.

The removal and recycling of ferrous materials is useful, and a grinding process prior to Fe-separation increases the heavy metal content in other fractions by abrasion and impact (Bidlingmaier 1990). Magnetic separators should be installed before and after the grinding process to remove the $\mathrm{Fe}$-fraction to a large extent.

Table 1 shows the mass balance of a new mechanicalbiological treatment facility for RMSW in northern Germany. The facility has a capacity of approximately $30000 \mathrm{t} / \mathrm{a}$. The mesh size of the sieve drum is $100 \mathrm{~mm}$ to separate the RDF stream (Tegtmeyer 1997).

\section{Effect of biological treatment}

The aim of the biological treatment is the degradation of the organic components of RMSW. During the aerobic biological treatment the organic matter is degraded under heat release to carbon dioxide, water and biomass.

Table 1. Mass balance of the mechanical treatment step of a new facility (Tegtmeyer 1997)

\begin{tabular}{ll}
\hline Objective & $\%$ by weight \\
\hline Interfering materials & 3 to 5 \\
Fe-metals for recycling & 2 \\
High calorific fraction (RDF) & 12 to 15 \\
Input biological treatment & 78 to 83 \\
\hline
\end{tabular}

The degradation of organics in RMSW can be described by means of the reduction in VS. After mechanicalbiological pretreatment the VS content of the waste to be landfilled amounts to between 20 and $40 \%$ by weight depending on the waste composition. As already mentioned, the limit of $5 \%$ according to the thresholds given by 'Technische Anleitung Siedlungsabfall' (TASi; technical regulation of MSW) in Germany cannot be met.

However, it needs to be taken into consideration that for the determination of VS the total content of organic carbon compounds in MSW has to be determined. Non-degradable or not readily degradable components like plastics, rubber, and leather are also included. For this reason the VS parameter is not suitable to describe the biodegradable potential of MSW. Any biological activity can be determined more expressively by measuring the oxygen consumption of wastes.

The so-called respiration rate is determined, for example, by a Sapromat (Voith, Heidenheim, Germany). The respiration rate of RMSW during biological treatment is presented in Fig. 1. Subsequently, RMSW was sieved in a rotating sieve drum of $<80 \mathrm{~mm}$ and thereafter any sieve undersize was composted in a windrow which was turned over weekly. The same type of RMSW (grain size $<80 \mathrm{~mm}$ ) was exposed to forced aeration in a composting container. For the respiration test the waste was sieved again and a particle size less than $20 \mathrm{~mm}$ was used. The samples were adjusted to a water content of $50 \%$. The oxygen consumption was determined after $96 \mathrm{~h}$ and was related to dry matter (dm) (Leikam \& Stegmann 1996).

After an approximate 16-week composting period the respiration rate is reduced by more than $80 \%$ to about $5 \mathrm{mg}$ $\mathrm{O}_{2} \mathrm{~g}^{-1} \mathrm{dm} * 96 \mathrm{~h}^{-1}$. The phase of intensive biological degradation is terminated after about 10 to 12 weeks, thereafter only a minor reduction of the respiratory activity is to be found. There is no significant difference between composting in windrows and closed containers. Fricke et al. (1995) measure a similar decrease in the respiration rate during residual waste composting. In this case the respiratory activity is reduced after 16 weeks by more than $75 \%$ and after 24 weeks by about $95 \%$.

Previous investigations show that the respiration rate is a suitable parameter to quantitatively describe the degree of maturity during composting. By measuring the respiration activity it becomes obvious that the biodegradable potential of residual waste can be significantly reduced by composting. A respiration rate $\leq 5 \mathrm{mg} \mathrm{O}_{2} \mathrm{~g}^{-1} \mathrm{dm} * 96 \mathrm{~h}^{-1}$ is recommended by the authors to define a biological stable material. 


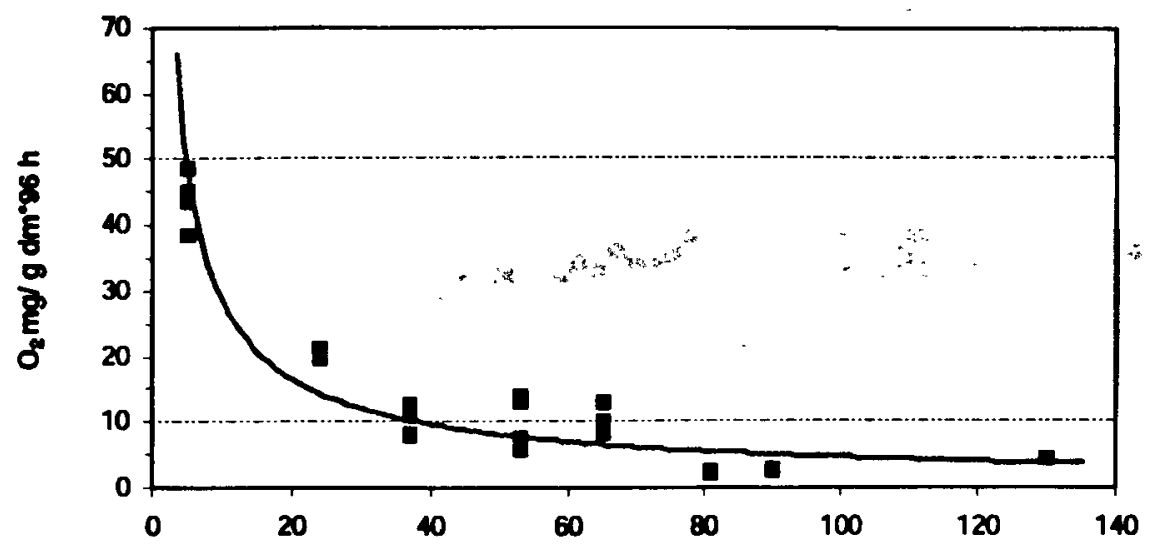

Fig. 1. Respiration rate during composting of RMSW ( $<80$ mm, full-scale plant: Leikam \& Stegmann 1996).

container composting

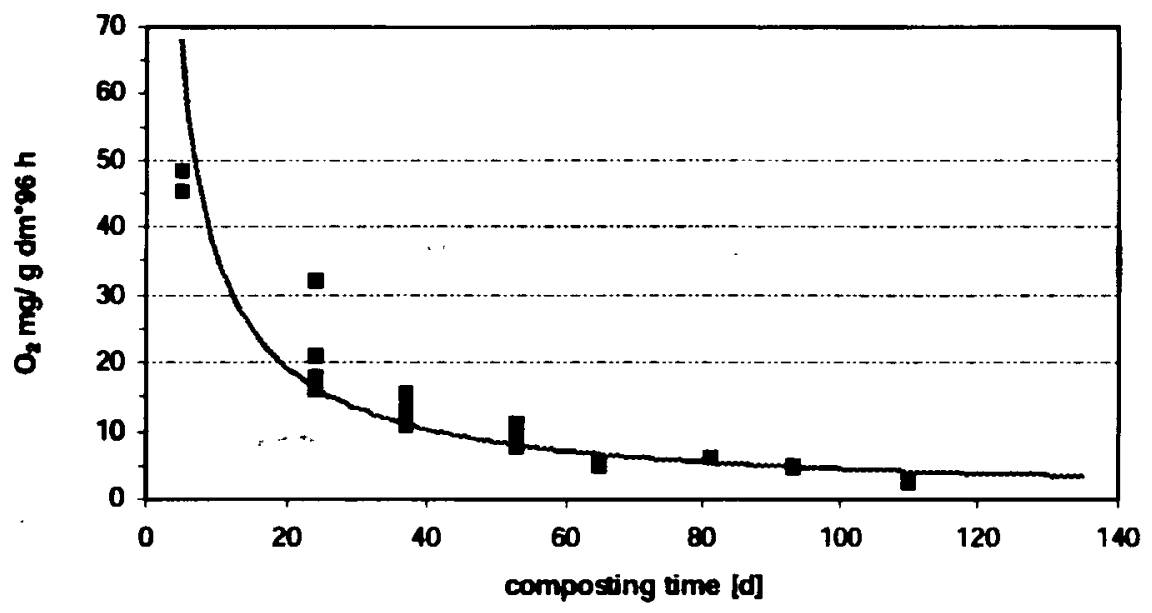

Influence of mechanical-biological pretreatment of RMSW on landfill behaviour

\section{Mass reduction and density}

Mass reduction during biological treatment is determined via the decrease in water content and organics. Depending on the individual treatment concept, the mass reduction amounts to between 20 and $40 \%$.

The density of landfilled biologically pretreated RMSW after compaction is expected to increase from about 0.8 to $0.9 \mathrm{Mg} \mathrm{m}^{-3}$ to 1.2 to $1.4 \mathrm{Mg} \mathrm{m}^{-3}$. As a consequence, settling of the waste in the landfill body will be significantly reduced or avoided. Compared with non-pretreated RMSW, up to 20 to $30 \%$ volume may be saved as a result of the mass reduction and a further $30 \%$ on account of the high density of the landfilled material. In total the volume will be reduced up to 50 to $60 \%$ by volume in relation to non-pretreated waste (Hcerenklage \& Stegmann (1995).
Landfill emissions

To describe the landfill behaviour of residual waste after biological pretreatment, landfill simulation experiments have been carried out under anaerobic conditions. The test system ensures that typical landfill phases such as the acid phase and stable methane phase take place in the reactors (Stegmann 1981). By choosing appropriate milieu conditions, an enhanced biological degradation process is achieved. By this means, the maximum emission potential represented by gas production and leachate load can be determined within reasonable periods of time.

Untreated RMSW and composted RMSW samples were investigated in landfill simulation tests. Fig. 2 shows curves of selected leachate parameters for untreated and pretreated RMSW. The untreated RMSW was only homogenized, and pretreated RMSW was derived from the same waste type but sieved (grain size $<80 \mathrm{~mm}$ ); and the sieve undersize 
Fig. 2. $C O D, T O C$ and $N_{\text {total }}$ in leachate during landfill simulation tests with an untreated residual waste sample (water flow to dry malter ratio $-1.6: 1$ affer $400 \mathrm{~d}$ ).
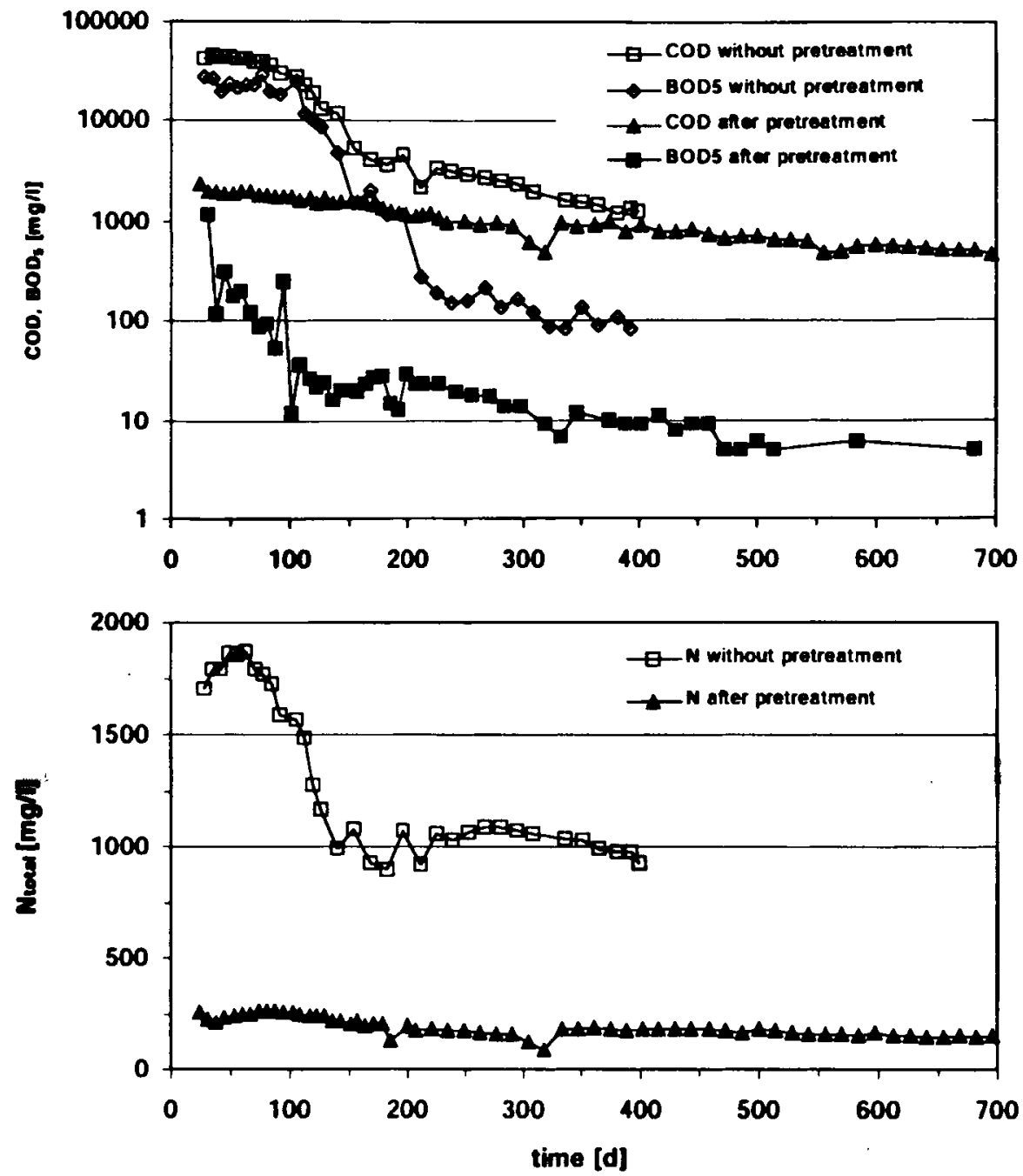

composted in a container for 4 months. The respiration rate at the end of composting amounted to $\leq 5 \mathrm{mg} \mathrm{O}_{2} \mathrm{~g}^{-1}$ dm*96 h (see Fig. 1).

For pretreated RMSW the acidic phase, during which highly loaded leachate is produced in the landfill body, is omitted. After about 250 test days the COD content in the leachate is below $1000 \mathrm{mg} \mathrm{l}^{-1}$. At this time the $\mathrm{BOD}_{5}$ concentration is only at $20 \mathrm{mg} \mathrm{l}^{-1}$. It should be taken into consideration that, when compared with the water flow rate, an investigation time of 250 days corresponds to a period of approximately 50 years for a large-scale landfill of $20 \mathrm{~m}$ in height with an annual leachate production rate of $250 \mathrm{l} \mathrm{m}^{-2}$ (water flow to dry matter - ratio $1: 1$ ).

The positive effect of pretreatment becomes evident when the nitrogen parameter is taken into consideration (see Fig. 2). Whereas the total nitrogen content in the leachate of untreated residual waste adjusts at about
$1000 \mathrm{mg} \mathrm{TN} \mathrm{l}^{-1}$, this value is below $200 \mathrm{mg} \mathrm{TN}^{-1}$ for pretreated RMSW. Besides a very much lower expenditure for leachate purification, a shorter period of landfill aftercare may be expected, since the time of aftercare is dependent on the nitrogen parameter (Heyer et al. 1996).

When landfill conditions are simulated in laboratory tests, leaching processes are very important, particularly during the methane phase. For this reason, the comparison of leachate emissions of untreated and pretreated residual waste is made via the emitted loads. Leaching processes are determined via the specific new leachate production rate. Of the leachate components determined in the landfill simulation tests the parameters COD, TOC and total nitrogen are represented in Fig. 3 for one sample of untreated RMSW, one RMWS sample after a 4-month composting period and one sample of incinerator bottom ash. 
Cumulative COD Load in Leachate

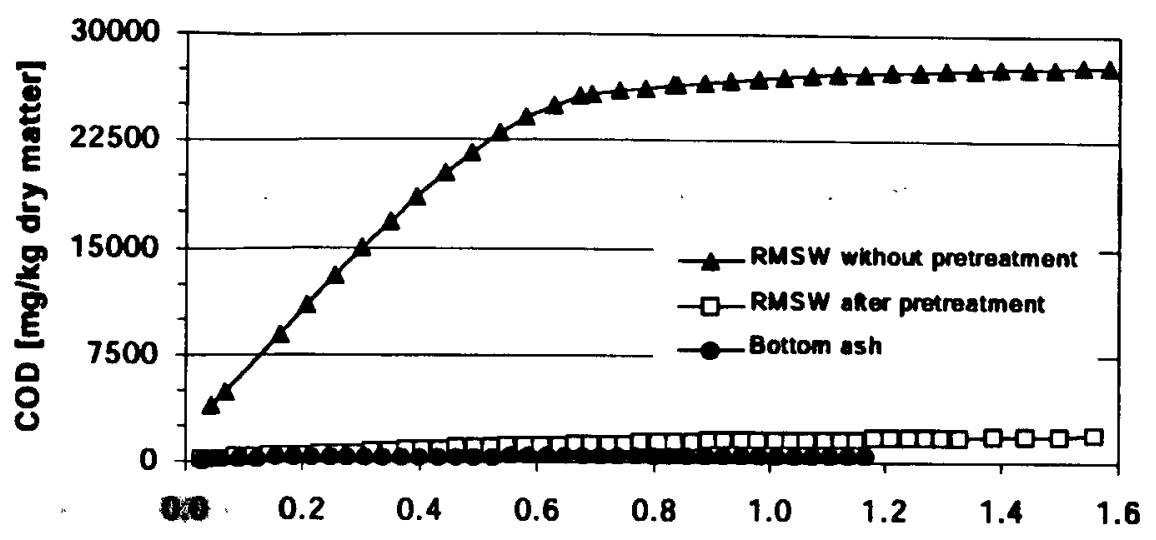

Fig. 3. Total COD, TOC and nitrogen load for an untreated, biologically (4-month) and thermally pretreated RMSW in landfill simulation tests.

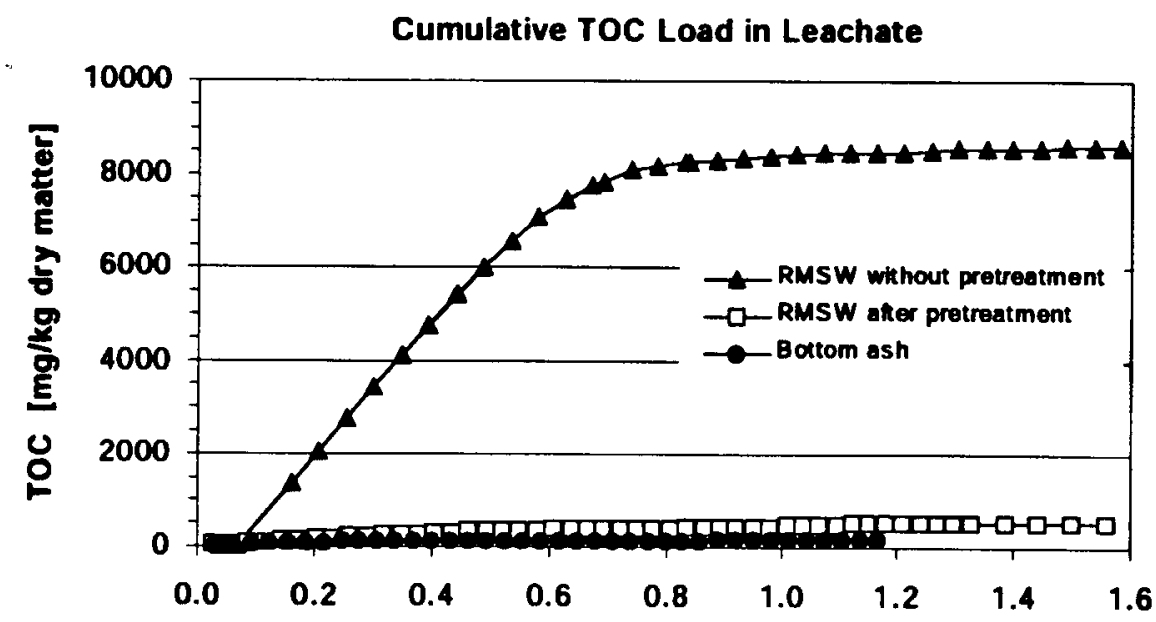

Cumulative Total Nitrogen Load in Leachate

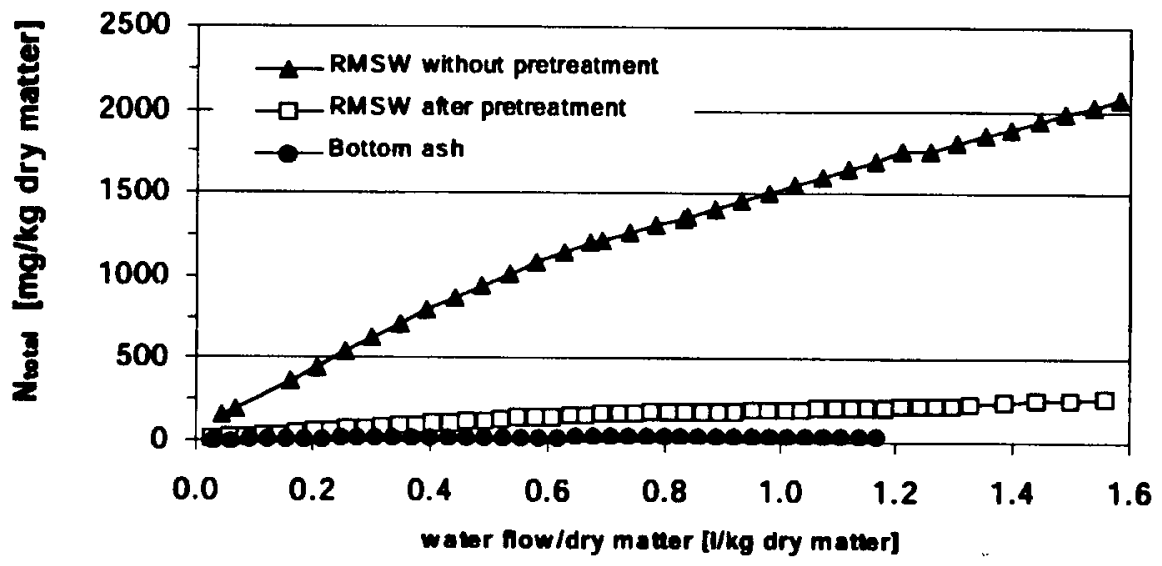

Comparing the emitted load the efficiency of mechanicalbiological pretreatment becomes obvious. For a ratio of water flow to dry matter of 1.0 (i.e. the amount of landfilled waste was brought into contact with the same amount of water which corresponds to a period of about 50 years) the mass transfer was $90 \%$ lower for biologically pretreated waste than for untreated RMSW. As mentioned above, the period of aftercare is considerably shorter, especially due to the reduction of the nitrogen load.

As a result of the high degree of incrtization of the incinerator bottom ash the leachate load is reduced by $98 \%$; however, the difference in the emitted loads for biologically pretreated RMSW and incineration slag is relatively small compared with untreated RMSW. 
When comparing the landfill gas production of untreated and pretreated RMSW in landfill simulation experiments it becomes obvious that the landfill gas emission potential is also significantly reduced due to biological pretreatment. For untreated residual waste the landfill gas quantity amounts to about $200 \mathrm{l} \mathrm{kg}^{-1} \mathrm{dm}$. The cumulative gas quantity of pretreated residual waste amounts to about $20 \mathrm{l} \mathrm{kg}^{-1}$ dry matter, which means that the landfill gas emission potential is reduced by about $90 \%$.

\section{Landfill operation}

The gas production rate of biologically pretreated RMSW after landfilling depends on the degree of maturity reached during composting. IfRMSW is composted for a period of more than 6 months, gas extraction may not be necessary. In this case a compost layer may be placed on top of the surface of the landfill. The compost layer with a low density should have a high proportion of structural material. The methane emitted from the landfill can be oxidized to $\mathrm{CO}_{2}$ in this layer due to microbial activity (Figueroa 1993). By this means methane emission into the atmosphere can be reduced or even avoided. If the landfill surface is sealed by a liner, the methane oxidation in a compost layer cannot be realized. In this case either periodical artificial gas extraction or other measures have to be applied in order to avoid gas accumulation in the landfill that may occur over longer periods of time.

Since the density of the waste is very high leachate as well as the gas migration through the landfill may be problematic. This open question is subject to further investigations.

\section{References}

Bidlingmaier, W. (1990) Schwermetalle im Hausmüll - Herkunft, Schadwirkung und Analyse. Stuttgarter Berichte zur Siedlungswasserwirtschaft, Vol. 42. Bielefeld, Germany: Erich Schmidt-Verlag.

Figueroa, R. A. (1993) Methane oxidation in landfill top soils. Proceedings Sardinia ' 93 , 4th International Landfill Symposium. Cagliari, Italy: CISA, 701-715.

Fricke, K., Müller, W., Ganser, G., Köbl, R. \& Turk, T. (1995) Mechanisch - Biologische Restmüllbehandlunganlage Quarzbichl- Massenbilanz, Stabilität der organischen Substanz und Qualität des Eluats. In: Wiemer, K. Kern, M. (eds.) Abfall-Wirtschaft-Neues Aus Forschung und Praxis. Witzenhausen, Germany: MIC Baeza-Verlag.

Heerenklage, J. \& Stegmann, R. (1995) Overview on mechanical-biological pretreatment of residual MSW. Proceedings Sardinia '95, 5th Intemational Landfill Symposium. Cagliari, Italy: CISA, pp. 913-925.

Heyer, K.-U., Packert, A. \& Stegmann, R. (1996) Untersuchungen zum langfristigen Emissionsverhalten von Abfällen im Deponiekörper. Müll und Abfall. Heft 4/96, S. 230-241. Berlin, Germany: Erich Schmidt-Verlag.

Leikam, K. \& Stegmann, R. (1995) Mechanical and biological treatment of

\section{Conclusions}

Landfill emissions can be significantly reduced when the waste is mechanical-biologically pretreated prior to landfilling. Mechanical-biological pretreatment of residual wastes represents an alternative to incineration. However, when landfilling residues in Germany the limiting value of $5 \%$ VS (TASi) has to be respected. Using mechanicalbiological processes this target cannot be reached. The VS parameter is suitable for quantitative examination of the combustion residues, but not for the residues from mechanical-biological treatment. To characterize biodegradable potential, biological test procedures such as the determination of the respiration rate of the residual waste are more suitable. The respiration rate is reduced during biological treatment by between 90 and $95 \%$ depending on the degree of composting, and landfill behaviour of pretreated waste is significantly improved. Additionally, COD and total nitrogen in the leachate will be reduced by about $90 \%$. The gas production rate for pretreated residual waste amounts to about $201 \mathrm{~kg}^{-1} \mathrm{dm}$, thus being $90 \%$ lower than for untreated RMSW. In addition, the landfill properties of pretreated waste are improved and by the increased density of the waste, only minor settlings will take place in the landfill body. Thus, the volume to be landfilled will be reduced by mechanical-biological pretreatment by up to $60 \%$.

residual waste before landfilling. Proceedings Sardinia '95, 5th Intemational Landfill Symposium. Cagliari, Italy: CISA, 947-955.

Leikam, K. \& Stegmann, R. (1996) Stellenwert der mechanischbiologischen Restabfallvorbehandlung. Abfallwirtschafts Journal 9, 39-44.

Stegmann, R. (1981) Beschreibung eines Verfahrens zur Untersuchung anaerober Umsetzungsprozesse von festen Abfallstoffen im Deponiekörper. Müll und Abfall 2, 35-41.

Stegmann, R. (1994) Chancen biologisch-mechanischer Behandlungsverfahren vor der Deponierung. Wasser und Boden 5,21-26.

Stief, K. (1993) Requirements for MSW Landfills in Germany. Proceedings Sardinia ' 93, 4th International Landfill Symposium. Cagliari, Italy: CISA. 9. 19.

Tegtmeyer, E. (1997) Stand der Technik der mechanisch-biologischen Abfallbehandlung im Technologieverbund, Erfahrungen aus dem Betrieb - Beispiel: Technologisch aufwendige MBV-Anlage Lüneburg, 5 Münsteraner Abfallwirtschaftstage. Hrsg. Gallenkemper,

Bidlingmaier, Doedens, Stegmann. 179-183. 